\title{
Material Requirements Planning System Infusion
}

\author{
RB COOPER \\ University of Michigan, USA \\ RW ZMUD \\ Flonda State University, USA
}

(Received April 1988, in revised form April 1989)

\begin{abstract}
There is increasing pressure upon manufacturing firms to make their processes more efilcient and effective. An important factor for improving these manufacturing processes is production and inventory management, and a variety of production and inventory management information systems such as Material Requirements Planing (MRP) have thus been developed. However, MRP has a significant history of beplementation problems. To help explain why these problems occur, this paper examines factors afiecting MRP implementation from a innovation diffusion perspective. Within this perspective, the effect of manufacturing tasks and MRP technology on the infusion of MRP are examined. Data are gatherered via longitudinal telephone survey of US manufacturing firms to determine these effects. A logiatical regresion analysis of the data indicates that factors such as production conplexity which affect MRP adoption can work in an opposite direction for MRP infusion (the use of MRP to its "fullest potential"). This implies that it may be advantageous for some firms to adopt and maintain MRP at low infusion levels rather than attempting to increase infusion over time. These results belp explain some of the problems currently associated with MRP implementation and help point out potential problem areas for those contemplating MRP implementation.
\end{abstract}

Key words-material requirements plannıng, information system implementation, diffusion of innovations

\section{INTRODUCTION}

THERE is increasing pressure upon manufacturing firms to make their processes more efficient and effective. An important factor for improving these manufacturing processes is production control. A variety of information sys-

' Material Requirements Planning (MRP) uses information on future finished goods demand and an integrated model of the entire production process in order to determine the appropriate tuming and amount of materials to purchase and produce An important distinguishing factor of MRP is that the required timing and amount of a specific component are derived from (dependent upon) requirements for higher level components and ultımately future finished goods demand For example, for every car demanded, four wheels are required, for every wheel required, four lug nuts are required. etc In contrast, reorder point models determine the required purchase or manufacture of a component by focusing upon its histoncal usage independent of higher level component requirements. Thus, the requirement for lug nuts is based upon an independent forecast of lug nut usage and not directly linked to the forecast for wheels or cars tems to support production control such as Material Requirements Planning (MRP)' and Optimized Production Technology (OPT) have thus been developed to replace the traditional reorder point-based information systems. Of these new information systems, MRP has had the most extensive implementation [1]. This paper focuses upon MRP and its replacement of traditional reorder point-based systems because, though extensively implemented, MRP has a significant history of problems. For example, though MRP has been acclaimed as making traditional reorder point-based systems obsolete [43], as Plossl [30] notes:

"never... has so much been proclaimed and expected and so little actually delivered."

While MRP is highly promoted, many problems are still occurring with MRP implementation $[31,44]$. This paper examines some of the factors affecting MRP implementation in order to help understand why these problems occur and to 
help those contemplating MRP implementation avoid such problems.

Prior MRP research identifies many factors which may contribute to MRP implementation problems. For example, inaccurate data, poor integration with other information systems, and lack of top management support have all been reported as causes of such difficulties. However, this research has suffered from the lack of a directing and organizing framework there is no indication whether important research issues have been overlooked and what these issues might be. To aid in directing MRP implementation research, an information systems implementation model developed by Kwon and Zmud [21] is adopted here. This model draws upon the well established innovation and technological diffusion literatures and provides a framework in which to place and evaluate current MRP implementation research efforts.

When evaluated in terms of this implementation model, we found in an earlier paper [14] that potentially important model elements have not been addressed by MRP researchers. This study builds upon the earlier work to further our understanding of the MRP implementation process.

\section{INFORMATION SYSTEMS IMPLEMENTATION MODEL}

Viewed from the technological diffusion perspective, information systems implementation is defined as organizational effort directed toward diffusing appropriate information technology within a user community. From this perspective, factors facilitating and inhibiting MRP implementation can be identified in order to help managers decide upon the potential for successful MRP implementations in their organizations.

Kwon and $Z$ mud [21] propose a stage model of information system implementation activities based upon the diffusion literature and organized around Lewin's [24] change model. A variation of their stage model developed by Cooper and Zmud [14] is presented below.

\section{Initiation}

- Process: Active and/or passive scannıng of organizational problems/opportunities and information technology solutions are undertaken. Pressure to change evolves from etther organizational need (pull), technological innovation (push), or both.

- Product: A match is found between an information technology solution and its application in the organization.

\section{Adoption}

- Process. Rational and political negotıations ensue to get organizational backıng for implementation of the information technology application.

- Product. A decision is reached to invest resources necessary to accommodate the implementation effort.

\section{Adaptation}

- Process. The information technology application is developed, installed, and maintained. Organızational procedures are revised and developed. Organizational members are trained both in the new procedures and in the information technology application.

- Product- The information technology application is available for use in the organization

\section{Acceptance}

- Process Organizational members are induced to commit to information technology application usage

- Product: The information technology application is employed in organizational work.

\section{Routinization}

- Process Usage of the information technology application is encouraged as a normal activity.

- Product. The organization's governance systems are adjusted to account for the information technology application; the information technology application is no longer perceived as something out of the ordinary.

\section{Infusion}

- Process: Increased organizational effectuveness is obtained by using the information technology application in a more comprehensive and integrated manner to support higher level aspects of organizatıonal work.

- Product: The information technology application is used within the organization to its fullest potential [35] 
Reviewing and synthesizing the technology diffusion, organizational innovation, and information system implementation literatures, $K$ won and $\mathrm{Zmud}$ [21], found five major contextual factors which impact the stages of this model. These factors relate to characteristics of the user community (job tenure, education, resistance to change); characteristics of the organization (specialization, centralization, formalization); characteristics of the technology being adopted (complexity); characteristics of the task to which the technology is being applied (task uncertainty, autonomy and responsibility of person performing the task, task variety); and characteristics of the organizational environment (uncertainty). In addition, the interaction among these factors was shown to be important, such as the compatibility and economic advantage of the technology with organization and task characteristics.

\section{PRIOR RESEARCH INTO MRP IMPLEMENTATION}

Though there has been some research addressing the MRP adaptation stage (e.g. project management: $[5,20,41])$, most MRP implementation research has focused upon the acceptance stage, evaluating the impacts of technology and user community characteristics. For example, MRP technological characteristics which have been found to negatively impact MRP acceptance include inaccurate data $[2,9,15,16,18$, $31]$, inappropriate lot sizing techniques $[13,29,34]$, invalid master production schedules $[11,31]$, and poor integration of MRP with other information technology $[3,12]$. Similarly, the following user community characteristics have been found to affect the acceptance stage: user resistance to change has been found to be important, and methods from the organizational change literature have been suggested to overcome it $[2,8,28,36,40,42]$; the lack of MRP understanding seems to reduce the potential for successful implementation, and educational programs are suggested to increase this understanding $[2,15,16,25,32]$; and top management support has been found to be necessary for successful MRP implementation $[2,10,16,19]$.

Based upon analogous findings in the technological and innovation diffusion literatures, Cooper and $\mathrm{Zmud}$ [14] suggest that the yet unexamined impacts of task and technology upon various implementation model stages may be critical to successful MRP implementation. Their argument pursues the following line MRP technology was developed to deal with determining material requirements in manufacturing contexts where demand is dependent rather than independent. It is usually assumed that MRP is appropriate in contexts which generally meet these conditions. However, within this general classification of dependent demand, there is a large variation in manufacturing contexts. For example, dependent demand can occur within firms which have assembly line or job shop manufacturing methods, in firms which adopt make to stock or make to order marketing strategies, etc. Each of these different contexts leads to different demands for the production control task. Since diffusion research has found that compatibility of task with the technology is a significant positive factor in implementation [22,38], focusing on the compatıbility of the production control task with MRP technology is potentially important in understanding MRP implementation.

In their study, Cooper and Zmud [14] characterize MRP technology in terms of its underlying assumptions, such as (1) deterministic finished goods requirements and (2) independent processes. These assumptions can then be compared to the production control task in various manufacturing contexts, with assumption violations indicatıng a lack of compatıbility. Unfortunately, since an information system is a simplification of reality, all contexts will result in some violation of MRP assumptions. However, the diffusion literature indicates that it is the relative rather than the absolute advantage of a technology which is important [33] That is, the usefulness of a technology should be judged relative to its alternatives.

In this case, the most common alternative to MRP for production control is the traditional reorder point system [1]. Thus, the compatibility of MRP technology with a production control task should be evaluated in terms of the violation of MRP and reorder point assumptions. greater compatibility comes from less violation of MRP assumptions and greater violation of reorder point assumptions. This results in two more assumptions which can be used to characterize MRP technology: the reorder point 
assumptions of (1) continuous and constant inventory item usage, and (2) inventory item independence. Note that assumptions shared by both MRP and reorder point (such as constant purchase lead time) are not of interest here since the focus is on relative advantage.

Cooper and $\mathrm{Zmud}$ then reviewed the production literature seeking production control task characteristics which had the potential for MRP and reorder point assumption violations. They found two characteristics which can be easily identified and which tend to have this effect: manufacturing method and marketing strategy. Manufacturing method depicts production itself, and can be measured along a continuum ranging from continuous (or assembly or repetitive) to intermittent (or job shop). Marketıng strategy can also be measured along a continuum, ranging from all products made-tostock to all products made-to-order (including engineer to order and assemble to order).

Different manufacturing methods and marketıng strategies imply very different production control tasks. It was found that the MRP assumption of deterministic finished goods requirements tends to be violated in firms which make-to-order and in firms which have intermittent (or job shop) type manufacturing. In addition, it was found that the reorder point assumption of continuous and constant inventory item usage tends to be violated in firms which make-to-stock and in firms which have contınuous (or assembly line) type manufacturing. Finally, though no characterization was readily available which relates to the degree of process independence assumption violation, the degree of inventory item independence was ascertained by the average number of bill-ofmaterial levels used in manufacturing.

Based upon a random sample of 62 United States manufacturing firms, Cooper and Zmud identified a significant impact of technology and task (as defined above) upon MRP implementation. MRP adoption tended to occur when:

- manufacturing method is continuous (violation of reorder point continuous and constant inventory item usage assumption);

- marketing strategy is make-to-stock (violation of reorder point contınuous and constant inventory item usage assumption);

- bill of material levels are high (violation of reorder point inventory item independence assumption).

In addition, diffusion research indicates that technological complexity is a significant negative factor in implementation [38]. Cooper and $\mathrm{Zmud}$ argue that this is important for MRP for the following reasons. Because MRP attempts to include more detail than reorder point, more complex production control tasks will lead to relatively more MRP than reorder point system (software design) complexity. This increased complexity will in turn lead to increases in computer programming errors which will negatively impact MRP implementation success. Using the average number of parts, components, etc. per bill-of-material level to measure production (control task) complexity, Cooper and Zmud tested this hypothesized relationship and found it to be significant: increases in task complexity lead to decreases in MRP adoption.

Though Cooper and $\mathrm{Zmud}$ were able to find significant relationships among task, technology, and MRP adoption, they were unable to find such significance when examining the effects of task and technology upon MRP infusion (with infusion defined as moving from MRP use for priority plannıng to MRP use for both prority and capacity planning). It was concluded that this lack of significance supported Laudon's [23] contention that rational models of implementation behavior (such as relating implementation success to organizational efficiency or effectiveness gains) are most relevant for early implementation stages. It was then suggested that later implementation stages may be more appropriately viewed by political and learning models.

\section{DEVELOPMENT OF HYPOTHESES}

This study builds upon the Cooper and Zmud [14] study by re-examining the conclusion that rational models are less appropriate than polittcal models for the later stages of MRP implementation. The rationale for this conclusion was as follows:

Tangible benefits, such as increased inventory turnover and reduction in delivery lead ume, are regularly observed with low level (priority planning) usage $[7,9]$. However, along with these benefits come real 
organizational costs In addition to significant monetary outlays (between $\$ 100,000$ and $\$ 1,000,000$ for MRP adaptation [2]). MRP requires significant organizational changes. Given these costs, champions are required if higher MRP infusion is likely to occur [37,39].

The organizational changes required for low levels of MRP infusion are located mainly in the production and inventory departments. Since production and inventory managers are initially championing the implementation [2], any required operational or managerial work system changes can be initiated and completed by them, assuring a relatively smooth implementation. In contrast, higher infusion levels (pnonty plus capacity planning) require changes which encompass the whole firm, MRP becomes a new way to run the business, affecting marketıng, finance, and engineerıng as well as senior management [45]. Since MRP is typically viewed as production-onented [45], non-production managers have difficulty envisioning the substantial benefits which can arise from higher levels of infusion. These managers are thus either reluctant to become MRP champions or resist the MRP-induced changes. In addition, since the production and inventory departments are already accruing benefits from low-level usage, there is reduced motivation for the initial champion (the production/inventory manager) to pursue enhanced infusion in the face of the personal risk embodied in challengıng more senıor managers.

The effects of these individualistic perspectıves (bureaucratic self-interest. [37]) have frequently been found to outweigh organizational considerations in later implementation stages, and result in curtailed infusion activity $[6,47]$. Thus, the fallure of MRP implementation to move beyond low-level infusion even when manufacturing contexts are approprate can be understood as a very natural phenomenon

If this bureaucratic self-interest and the assoc1ated requirement for its political control are important for MRP infusion, then contextual factors such as task and technology should not impact infusion.

However, higher MRP infusion implies the involvement of a different group of managers doing different (though related) sets of tasks. Thus, a rational perspective viewing the infusion process as a cyclic phenomenon may be appropriate: this different set of managers must go through the initiation and adoption stages, new software must be adapted, etc. in a manner similar to that which the production control managers did in order to implement MRP for priority planning. Though the actors have changed, the compatibility and complexity arguments provided by Cooper and Zmud for examining the influence of task and technology on MRP implementation are still reasonable. Capacity planning requires the same kind of conceptual MRP model as priority planning, with the same kinds of assumptions, etc. The capacity planning task can vary significantly depending upon a firm's marketing strategy, manufacturing method, and degree of inventory item dependence. In addition, MRP capacity planning software complexity is a function of production complexity.

The question, then, is how are these factors different for firms with low versus high level MRP infusion? We start with the premise that a firm adopting MRP will tend to have a manufacturing context which is in accord with
MRP assumptions and violates reorder point assumptions. manufacturing strategy to stock, intermittent manufacturing method, and high inventory item dependence (as measured by average bill of material levels). In addition, the amount of production complexity, as measured by the average number of parts per bill of material level, will tend to be low. However, once MRP is adopted, and starts being used for priority planning, higher levels of infusion may not be automatic. Increased infusion may require the following:

(1) Marketing strategy. The adoption of MRP implies that the marketing strategy tends to be to stock rather than to order. When manufacturing to stock, the variety of products and the associated variety of impacts upon capacity tends to be more limited than if production is to order. This lack of variety implies relatively easier capacity planning. However, the use of computer tools by management becomes more of an advantage (assuming that they are still valid) the more complex the task. Thus we would look for higher infusion in firms which, though predominately making to stock, have some production to order.

(2) Manufacturing method. Higher level MRP infusion indicates that in addition to priority planning, MRP is being 
used for capacity planning. However, the efficacy of MRP for capacity planning is severely reduced in continuous or assembly process plants. For example, assembly lines are designed to handle a specific production capacity and have little flexibility in terms, e.g. of alternative routings. Capacity planning is thus embodied in the line. Since MRP adoption typically occurs in predominately continuous or assembly line plants, this mitigates the advantage of increasing the infusion level to include capacity planning. However, within the continuous/assembly end of the manufacturing method continuum, those firms which have more intermittent or job shop-like characteristics (e.g., batch flow or a combination of job shop and assembly in one plant) may make a capacity planning tool look relatively advantageous.

(3) Production complexity. The adoption of MRP implies that the production process is relatively non-complex. However, within the non-complex range of the complexity continuum, the use of computer tools by management becomes more of an advantage (assuming that they are still valid) the more complex the task. Thus we would look for firms with somewhat higher complexity production processes to have higher levels of infusion.

(4) Inventory item dependence. Such dependence is a factor which is a comparative advantage for MRP. Thus, high inventory item dependence associated with MRP adoption should also be associated with MRP infusion.

These arguments lead to the following hypotheses. After MRP has been adopted, higher levels of MRP infusion are associated with:

$\mathrm{H}_{1}$ : Marketing strategies which, though predominately make to stock, have some production to order.

$\mathrm{H}_{2}$ : Manufacturing methods which, though predominately continuous, have some aspects of job shop production.

$\mathrm{H}_{3}$ : Production complexity (measured as parts per bill of material level) which, though in the simple portion of the complexity continuum, is relatively complex.

$\mathrm{H}_{4}$ : Inventory item dependence (as measured by the average number of bill of material levels) which is high.

\section{THE METHODOLOGY}

In order to test these hypotheses, the random sample of 62 United States manufacturing firms surveyed by Cooper and Zmud [14] were surveyed four years later. The same telepone interview approach was chosen to reduce confusion over terminology, to encourage a high response rate, and to enable comparison with the earlier study. Production managers and staff who wanted time to look data up were called back. Of the 62-firm sample, 12 were eliminated due to logistıcal problems (e.g., they moved with no forwarding address), because they had gone out of business, or because they transferred their manufacturing outside the United States. Hence, the results are based upon production managers and staff representıng a sample of 50 manufacturing facilities in the United States.

Respondents were asked about their firm's manufacturing method(s), marketing strategy(ies), average bill-of-material levels, etc. (For firms with multiple business units, respondents were instructed to answer relative to only one such unit.) Data were coded in the following manner. Manufacturing method was coded 0 for continuous and 1 for intermittent. Marketing strategy was coded 0 for make-to-stock and 1 for make-to-order. Most importantly, intermediate levels for both manufacturing method (e.g., 'batch flow') and marketing strategy (making to order and to stock) are represented by fractional numbers. Actual values were used for the average number of bill-of-material levels, and the average number of parts, etc. per bill-ofmaterial level.

In addition, respondents were asked what kind of manufacturing MIS was being employed. If they were using MRP, they were also asked to rate the system with the following $A$ through $D$ classification scheme suggested by Wight [46].

Class A-A closed loop system, used for priority planning and capacity planning. The master production schedule is leveled and used by top management to run the 
business. Most delıveries are on time, inventory is under control, and little or no expediting is done.

Class B-A closed loop system with the capability for both prionty planning and capacity planning. In this case, the master production schedule is somewhat inflated, top management does not give full support, and some inventory reductions have been obtained, but capacity is sometımes exceeded, and some expediting is required.

Class $\boldsymbol{C}$-An order launching system with priority planning only. Capacity plannıng is done informally, typically with an inflated master production schedule Expediting is used to control the flow of work and a modest reduction in inventory is achieved.

Class $D$-The MRP system exists mainly in data processing. Many records are inaccurate. The informal system is largely used to run the company. Little benefit is obtained from the MRP system.

In most cases the descriptions were read to the respondents and a discussion of their manufacturing MIS environment ensued. All firms included in the survey that were not using MRP were usıng traditional reorder point-based systems.

Table 1 depicts the survey respondent profile by industry, employing a classification scheme taken from Anderson et al. [2]. The industry profile of this survey is similar to the Anderson survey, with a majority of respondents from
Table 2 Respondents classified by state

\begin{tabular}{lcc}
\hline State & $\begin{array}{c}\text { Number of } \\
\text { companies }\end{array}$ & $\begin{array}{c}\text { \% of } \\
\text { total }\end{array}$ \\
\hline Arizond & 1 & 2 \\
Cdifornid & 6 & 12 \\
Connecticut & 1 & 2 \\
Georgid & 1 & 2 \\
Illinols & 4 & 8 \\
Indiana & 1 & 2 \\
lowa & 1 & 2 \\
Kansas & 1 & 2 \\
Kentucky & 1 & 2 \\
Massachusetts & 4 & 8 \\
Michigan & 4 & 8 \\
Minnesotd & 3 & 6 \\
New Hampshire & 2 & 4 \\
New Jersey & 4 & 8 \\
New York & 7 & 14 \\
North Carolina & 1 & 2 \\
Ohio & 2 & 4 \\
Pennsylvanid & 3 & 6 \\
Texas & 1 & 2 \\
Utah & 1 & 2 \\
Washington & 1 & 2 \\
\hline Total & 50 & 100 \\
\hline
\end{tabular}

metal working and electrical/electronic industries. A major difference between the Anderson survey and this survey is a shift in respondents from transportation and miscellaneous to electrical/electronic. One reason for this shift is the difference between sampling methodologies. While Anderson's survey was restricted to the midwestern portion of the United States, this survey sampled from the entire continental United States (see Table 2). As a result, more electronic manufacturers (e.g. computer-related manufacturers) were picked up from the east and west coasts.

Table I Industry and MRP use classification profile

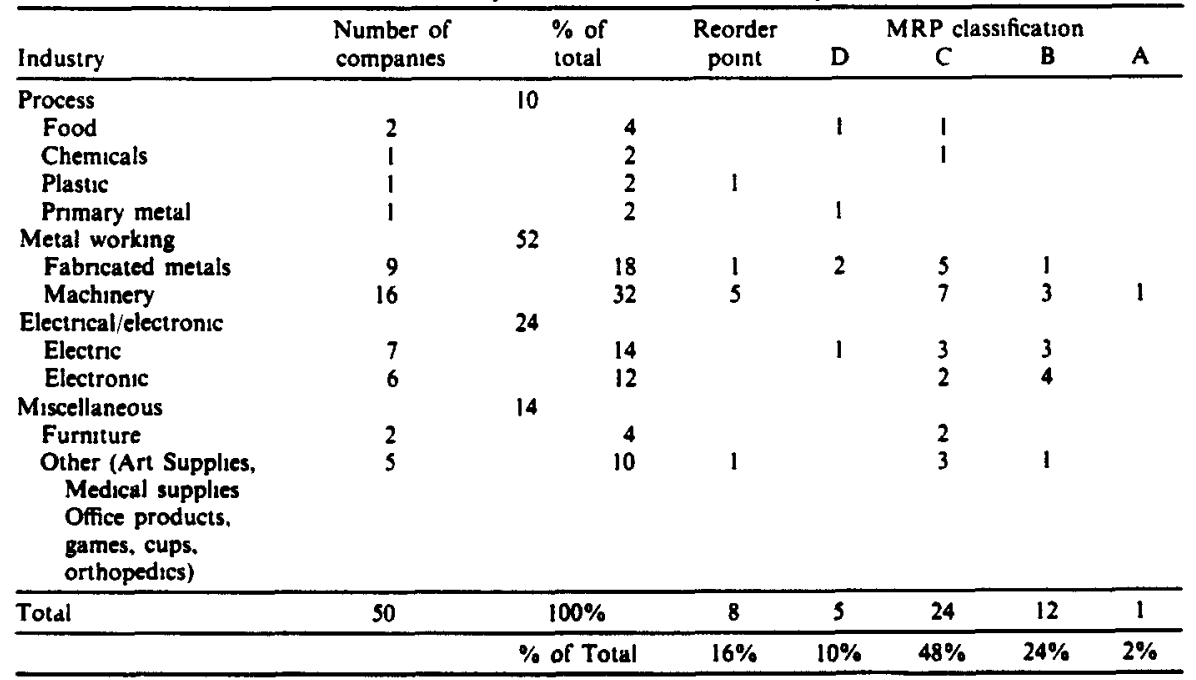


Table 3A Logistic regression for MRP infusion C versus $B$ and A

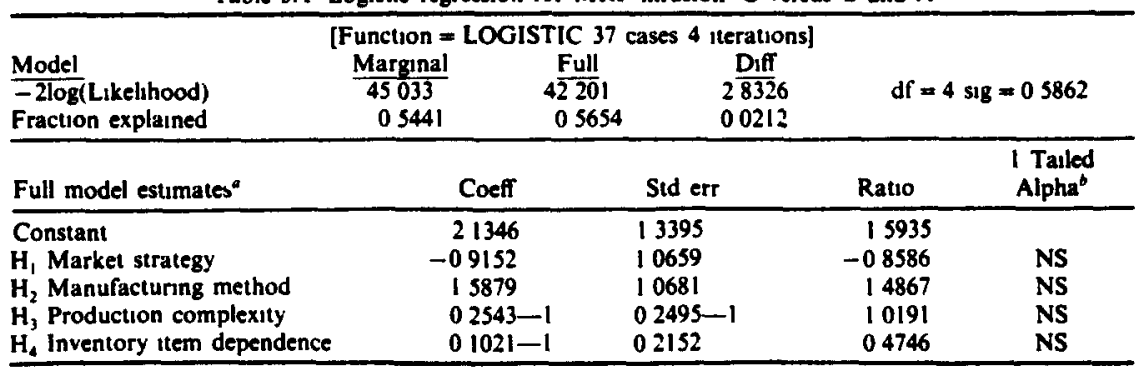

Table 3B Logistic regression for MRP Infusion $D$ and $C$ versus $B$ and $A$

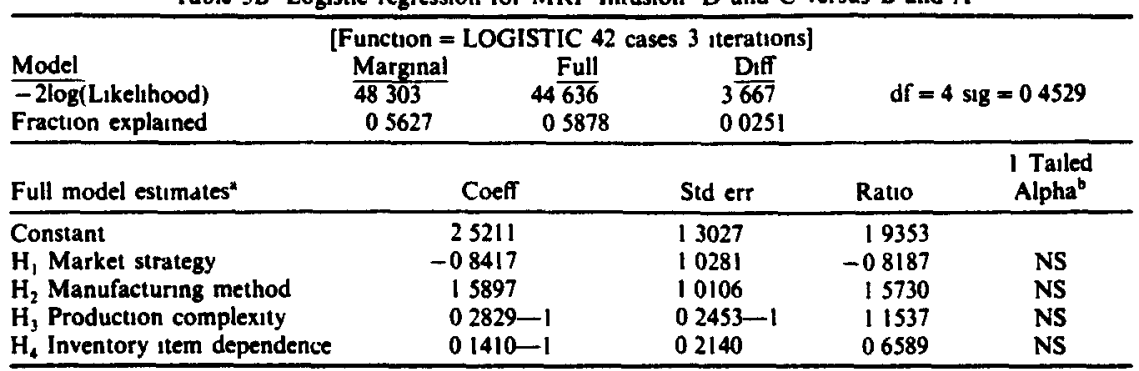

${ }^{a} H_{1}$ Market strategy is make-to-stock (coded 0 ) versus make-to-order (coded 1 ), with combination strategies coded between these two values

$\mathrm{H}_{2}$ Manufacturing method is contınuous (coded 0 ) versus intermittent (coded 1) manufacturing, with combination methods coded between these two values

$\mathrm{H}_{3}$ Production complexity is measured by the average number of parts, etc per bill-of-material level

$H_{4}$ Inventory item dependence is measured by the average number of bill-of-material levels

"Significance at alpha $=005$ NS means not significant at this level

Table 4A Logistic regression for change in MRP infusion from $C$ to $B$ or $A$

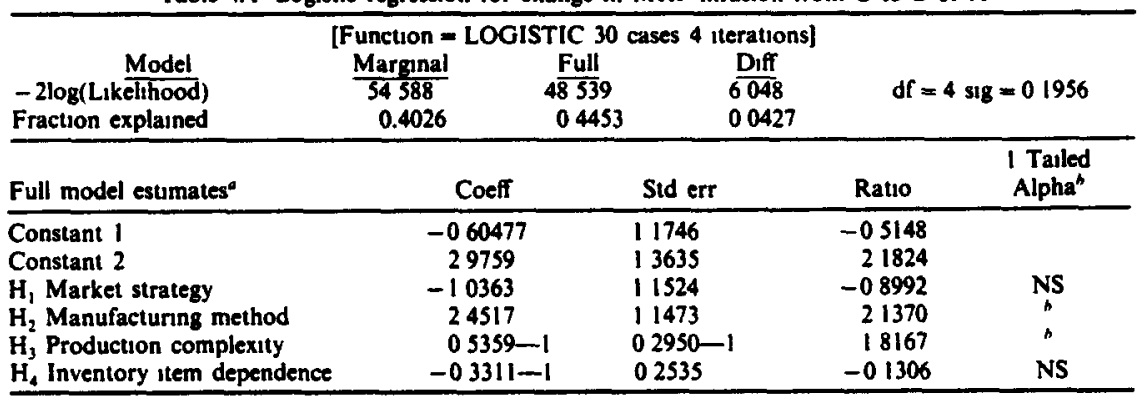

Table 4B Logistic regression for change in MRP infusion from $D$ or $C$ to $B$ or $A$

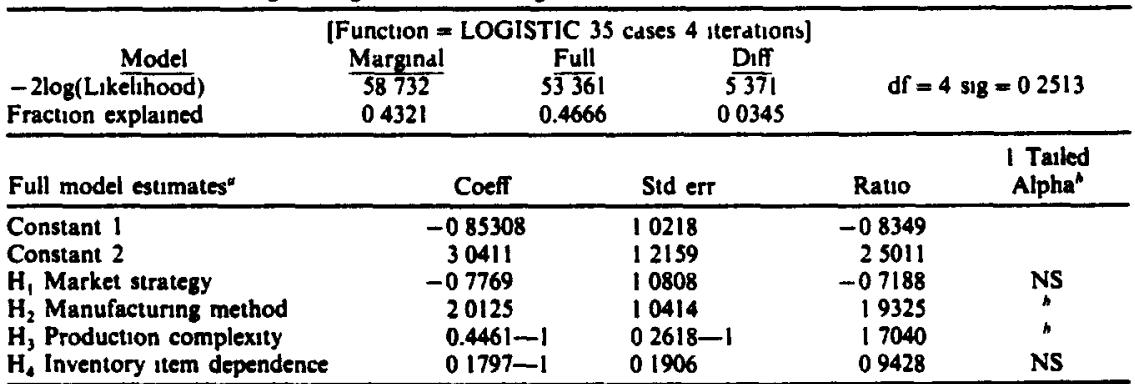

${ }^{-} H_{1}$ Market strategy is make-to-stock (coded 0 ) versus make-to-order (coded 1 ), with combination strategies coded between these two values

$\mathrm{H}_{2}$ Manufacturing method is continuous (coded 0 ) versus intermittent (coded I) manufacturing, with combination methods coded between these two values

$H_{3}$ Production complexity is measured by the average number of parts, etc per bill-of-material level

$\mathrm{H}_{4}$ Inventory item dependence is measured by the average number of bill-of-materal levels

"Significant at alpha $=005 \mathrm{NS}$ means not significant at this level 


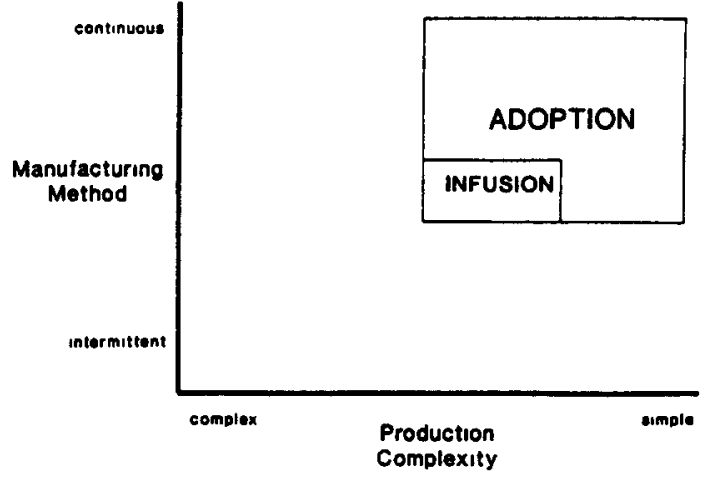

Fig I Effects of contextual factors on MRP adoption and infusion

\section{RESULTS}

Hypotheses 1-4 focus upon factors which, when existing over time, lead to change from low-level MRP infusion to higher-level MRP infusion. Thus the independent variables are calculated as averages using responses from the first survey [14] and this survey. Assuming that steady state has been reached by the time of the second survey, the dependent variable is the infusion level found in that survey, with 1 indicatıng $C$ class use and 2 indicating $B$ or $A$ class use. (Only one firm in the survey has $A$ class use, so it is combined with the B class firms.) Because of the dichotomous dependent variable, a logistic regression model (logit) is used to test the hypotheses [4].

Table 3A provides the results; the reduction from 50 to 37 firms is due to the exclusion of D class and reorder point using firms. None of the hypotheses are supported. Though firms using class D MRP have not attained even low-level infusion, they had passed the adoption stage and are in the process of adaptation with the intention of at least $C$ level usage. Thus, a reasonable case can be made that they should be grouped with those already using MRP at a C level in order to test the infusion hypotheses. Table 3B provides these results, with the increase in five firms representing the addition of those at a class D level. Again, none of the hypotheses are supported.

The rationale for using the final infusion level as a dependent variable is based upon the assumption that the firms have reached steady state by the time of the second survey. Since this is not necessarily the case, the hypotheses are again tested with the dependent variable calcu- lated as the change in infusion level during this time period. Movement from $C$ class use to $B$ or A class use is coded as 3 , no movement is coded as 2 , and movement from $A$ or $B$ class use to $C$ class use is coded as 1 . Because of the trichotomous dependent variable (positive, no change, or negative), a logistic regression model (logit) is used to test the hypotheses [4].

Table 4A provides the results. The reduction from 50 to 30 firms represents the exclusion of $D$ class and reorder point using firms. This amount is different from that in Table $3 \mathrm{~A}$ because this constraint is placed upon firms in both surveys rather than just in the last survey. Hypotheses 2 and 3 are supported (at alpha $=0.05$ ). The argument above for including class $D$ with class $C$ using firms leads to a second dependent variable with the results in Table 4B. As illustrated, the same two hypotheses are supported.

\section{DISCUSSION}

The lack of significance in the first set of tests and the significance associated with the second sets of tests suggests that firms using MRP are not yet at steady state. This may be due to the time it takes to naturally progress through MRP infusion or it may indicate a continued adjustment to external factors such as increased competition, market decline, changes in strategy, etc.

The significance associated with $\mathrm{H}_{2}$ and $\mathrm{H}_{3}$ in the second set of tests supports the notion that different contextual factors are required for MRP adoption and infusion. In fact the lack of significance of $\mathrm{H}_{4}$ also supports this view. $\mathrm{H}_{4}$ refers to the existence of inventory item dependence. As discussed in Cooper and Zmud [14], such dependence is a positive factor for MRP adoption. What has been illustrated in Tables 4A and 4B is that it does not play a more important role in infusion than in adoption. Firms adopting MRP already have adequate levels of dependence for infusion to occur.

The lack of significance for $\mathrm{H}_{1}$ is puzzling. The argument relating the efficacy of capacity planning to the amount of product variety associated with different marketing strategies seems reasonable. However, some of this effect may be picked up by the manufacturing method: job shops tend to have more variety in their products than continuous flow shops. In 
fact, the correlation between manufacturing method and marketing strategy is positive and significant (rho $=0.40$, alpha $=0.05$ ), supporting this interpretation.

Fig. 1 illustrates these results. MRP adoption is facilitated when manufacturing is more continuous than intermittent and more simple than complex. However, once adopted, higher infusion is more likely to occur when there is more production flexibility and product variety (as indicated by an increase in intermittent aspects of production) and when production is more complex. The hypothesized reason for this is that the move from $C$ level usage to $B$ level usage applies MRP to a different set of tasks (capacity planning) than those for which it was initially implemented. Given the costs associated with developing and maintaining the MRP system for this new usage, a relative advantage must exist for infusion to occur [33]. As demonstrated with the survey data above, this advantage tends to exist in manufacturing contexts which are in the less extreme portions of those facilitating MRP adoption. For firms which have very simple and inflexible production and have a lack of product variety, $C$ level infusion may appropriately be the highest level of infusion. That is, such firms using MRP at the C level may be employing the technology to its fullest potential.

\section{STUDY LIMITATIONS}

The research strategy employed for this study was a sample survey. External validity thus was enhanced because data were collected from subjects in a natural setting and a sample was chosen to represent a known population. However, although the respondents represented a random sample, they were chosen from a pool of American Production and Inventory Control Society members. Since the Society is a professional group which actively promotes the use of MRP, there may be a bias toward MRP adoption and infusion in the sample as compared to the population of all manufacturers. Thus, the generalization of conclusions to all manufacturing firms should be treated cautiously.

Internal validity was affected by the fact that there was no control over independent and nuisance variables. In addition, the strength and range of variables studied were limited due to the need for reasonably fast and easily understood communication over the phone. As a consequence, the resulting data may be less accurate and the MRP implementation model may not include potentially important components, such as the nature of each firm's competution and their prior history regarding information technology.

An additional threat to internal validity concerns the lack of respondent anonymity. That is, responses may be biased by the methodological artifact that respondents are known to the researcher. However, in this case there does not seem to be any systematic bias. The major area where such bias might occur is in the classification of MRP use. This might occur, for example, because of the wide promotion of MRP as state-of-the-art within the American Production and Inventory Control Society. Society members may want to appear as if they are using state of the art technology. However, such a bias was not indicated given the similarity of this study's MRP use classifications with those of the Anderson et al. [2] anonymous mall survey.

\section{CONCLUSION}

In order to maximize the benefits from information technology investments, organizations must understand and manage their implementation processes. Major contributions of this study include the identification of significant factors that affect the infusion of MRP but which are opposite to those facilitating the adoption of MRP. In addition, we have demonstrated that managerial rationality can play an important part in the infusion process. This does not imply that the growing line of research examining information system implementation from political perspectives $[17,26,27]$ are improper. Rather, that in the MRP context, the rational view should be incorporated along with the political view in order to better understand infusion processes.

\section{REFERENCES}

1 Aggarwal SC (1985) MRP, JIT, OPT, FMS? Makıng sense of production operations systems Harv Busin Rev September-October, 8-12

2. Anderson JC, Schroeder RG, Tupy SE and White EM (1981) Material Requirements Planning. A Study of Implementation and Practice Amencan Production and Inventory Control Society, Falls Church, Virginia. 
3 Bahl HC and Ritzman LP (1983) An empincal investıgation of different strategies for material requirements planning $J$ Ops Mgmt 3(2), 67-79

4 Ball CA and Tschoegl AE (1982) The decision to establish a foreign bank branch or subsidiary An application of binary classification procedures $J F_{i n}$ Quant Anal 17(3), 411-424

5 Beddick JF (1983) Elements of success-MRP implementation Prod Imv Mgmt 24(2), 26-32

6 Berman $P$ and McLaughlin MW Federal Programs Supporting Educational Change Implementing and Sustaining Innovations Rand Corporation, Santa Monica, R-1589/8-HEW

7 Bevis GE (1976) A management viewpoint on the implementation of a MRP system Prod Inv Mgmt (First Quarter), 105-116

8 Blasingame JW and Weeks JW (1981) Behavioral dimensions of MRP change Assessing your organization's strengths and weaknesses Prod Inv Mgmt 22(1), 81-95

9 Boxx DB (1979) MRP-selling a dead horse (or how to convince management to invest in MRP Prod Inv Mgmt (Second Quarter), 49-62

10 Brenizer NW (1978) MS to MRP to MSW Prod Inv Mgmt 19(3), 67-79

11 Brenizer NW (1981) The odyssey of inventory management Prod Inv Mgmt 22(2), 23-36.

12 Campbell RJ and Porcano TM (1979) The contributions of material requirements planning (MRP) to budgetıng and cost control Prod Inv Mgmt 20(2), 63-71

13 Collier DA (1980) A comparison of MRP lot sizing methods considering capacity change costs $J$ Ops Mgmt 1(1), 23-30

14 Cooper RB and Zmud RW (1989) Information technology implementation research. A technological diffusion approach. Mgmt Scl Forthcoming

15 Covin $S$ (1981) Inventory accuracy. One of your first hurdles Prod Inv Mgmt 22(2), 13-23

16 Fisher K (1981) How to implement MRP successfully Prod Inv Mgmt 22(4), 36-54

17 Franz CR and Robey D (1984) An investigation of user-led system design' Rational and political perspectives Commun ACM 27(12) (December), 1202-1209

18 French RL (1980) Accurate work in process inventory-A critical MRP system requirement Prod Inv. Mgmt (First Quarter), 17-22

19 Hall RW (1977) Getting the commitment of top management. Prod Inv. Mgmi 18(1), 1-9.

20 Hartley $\mathrm{K}$ (1983) How to plan and organize an MRP project Prod Inv Mgmt 24(1), 53-65.

21 Kwon TH and Zmud RW (1987) Unifying the fragmented models of information systems implementation In Critical Issues in Information Systems Research (Edited by Boland and Hirschheim) Wiley, NY.

22 Kimberly JR (1981) Managernal innovation (Edited by Nystrom PC and Starbuck WH), In Handbook of Organizational Design, Oxford University Press, London, 1, 84-104

23 Laudon KC (1985) Environmental and instututional models of system development. A national cruminal history system Commun ACM 28(7) (July), 728-740

24 Lewin K (1952) Group decision and social change, (Edited by Newcomb and Hartley). In Readings in Social Psychology, Henry Holt and Company, New York, 459-473
25 Maertz WE (1979) MRP's fourth requirement Prod Inv Mgmt 20(3), 81-84

26 Markus ML (1983) Power politics and MIS implementation Commun ACM 26(6), 430-444

27 Markus ML (1981) Implementation politics Top management support and user involvement Systems, Objectwes, Solutions 1, 203-215

28 Mehra S and Reid MJ (1982) MRP implementation using an action plan Interfaces 12(1), 69-73

29 Mather HF (1985) Dynamic lot sizing for MRP Help or hinderance?. Prod Inv Mgmt 26(2). 29-35

30 Plossl GW (1980) MRP yesterday, today, and tomorrow Prod. In $\mathrm{Mgm}$ Third Quarter, 1-9

31 Plossl GW (1985) Production and Inventory Control Principles and Techniques. Prentice-Hall, NJ

32 Roberts BJ (1982) Education and training programs to support MRP implementation, Prod Inv Mgmt 23(2), 45-64

33 Rogers EM (1983) Diffusion of Innovations, 3rd edn The Free Press, NY

34 St John R (1984) The evils of lot sizing in MRP Prod Inv Mgmt 25(4), 74-85

35 Sullivan C (1985) Systems planning in the information age Sloan Mgmt Rev Winter, 3-12

36 Teplitz CJ (1980) Is your organization ready for MRP? Interfaces 10(3). 103-106

37 Tornatzky LG, Eveland JD. Boylan MG, Hetzner WA. Johnson EC. Rottman D and Schneider J (1983) The Process of Technological Innovation Reviewing the Literature National Science Foundation, Productıvity Improvement Research Section. Division of Industrial Science and Technological Innovation, May

38 Tornatzky LG and Kleın K (1982) Innovation characteristics and innovation implementation. A meta-analysis of findings IEEE Trans Engng Mgmt 29(1) (February), 28-45

39 Van De Ven AH (1986) Central problems in the management of innovation, $\mathrm{Mgmt} \mathrm{Scl}$ 32(5), 590-607

40 Wacker J and Hills FS (1977) The key to success or fallure of MRP Overcoming human resistance Prod Inv Mgmt 18(4), 7-16

41 Weston FC (1983) The process of planning for MRP incorporating a systems viewpoint Prod Int Mgmt 24(2). 15-25

42 White EM (1980) Implementung an MRP system using the Lewin-Schein theory of change Prod Int Mgmt (First Quarter), 1-12

43 Wight OW (1974) Production and Incentory Management in the Computer Age. Cahners Books, Boston, MA

44 Wight OW (1982) The Executtice's Guide to Successful MRPII Prentice-Hall, NJ

45 Wight OW (1980) Tools for profit Datamation 26(10), 93-96

46 Wight oW (1977) Time for the annual checkup Newsletter

47 Yin RK, Heald KA and Vogel ME (1977) Tinkering with the System Lexington Books, Lexington, MA

ADDRESS fOR CORRESPONDENCE: Professor RB Cooper, School of Business Administration, Unuersity of Michigan, Ann Arbor, MI 48109-1234, USA 